\title{
O ABASTECIMENTO ENERGÉTICO EM CIDADES DA LINHA DO GASODUTO: GERAÇÃO E DISTRIBUIÇÃO DE ENERGIA ELÉTRICA NA CALHA DO SOLIMÕES
}

\author{
Abraão Ferreira Zuza \\ Mestrando do Programa de Pós-graduação em Geografia - UFAM \\ Universidade Federal do Amazonas \\ abraaozuza14@gmail.com \\ Paola Verri de Santana \\ Professora Doutora do Programa de Pós-graduação em Geografia - UFAM \\ Universidade Federal do Amazonas \\ pvsantana@yahoo.com.br
}

\begin{abstract}
RESUMO: O presente trabalho tem como objetivo principal identificar como se dá o abastecimento energético nas cidades da linha do Gasoduto Coari-Manaus. Tendo como base que já se passaram um período considerável de tempo em relação ao inicio das obras, e que de acordo com o banco de dados da Agência Nacional de Energia elétrica-ANAEL as cidades da linha são abastecidas a partir do gás natural, instiga-nos a investigar as reais situações relacionadas ao abastecimento energético da região. Buscando de todo modo, compreender os aspectos econômicos, sociais e ambientais que estão embutidos em todo contexto atual de geração de energia. Além disso, busca se identificar os sujeitos e embates que estão envolvidos nessa dinâmica, tendo em vista, que a partir da sociedade capitalista se observa uma considerável desigualdade, sobretudo, na repartição dos benefícios extraídos a partir da exploração dos recursos naturais.
\end{abstract}

Palavras-chave: Abastecimento energético, Cidades, Gasoduto.

\section{INTRODUÇÃO}

A energia elétrica é um dos elementos fundamentais para o desenvolvimento da sociedade moderna. Se analisarmos em seu contexto histórico, a partir de sua expansão o ser social teve acesso a novas maneiras de desenvolver suas atividades. Além disso, ela contribui nos diferentes setores da sociedade, representando assim um avanço inclusive para novas conquistas cientificas.

No Estado do Amazonas, com exceção de Manaus e região metropolitana, o abastecimento energético se dá em uma perspectiva de sistemas isolados. Tendo em vista a partir da extensão territorial do Estado, a população se torna com quantitativo pequeno. Sendo assim, o fornecimento ocorre a partir dos derivados do petróleo. No entanto se tem a expectativa de que na região do Solimões incialmente os municípios de Anamã, Anori, Caaparinga, Coari, Codajás, Iranduba e Manacapuru tenham usinas 


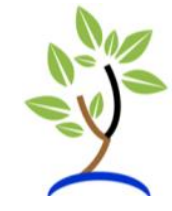

movidas a gás natural. Isso por que, o prazo para esse tipo distribuição de energia tendo como fornecedor o gasoduto Coari-Manaus, já está encerrado.

Nos últimos anos muitos pesquisadores têm desenvolvido estudos nas cidades que estão situadas na linha do gasoduto. Nesse sentido, se observa resultados relevantes que contribuem diretamente nesse processo. Mas, que diante do cenário de dinamismo presentes na sociedade, se entende que é necessário um aprofundamento nesses estudos, na busca por novos resultados, que possibilitarão novas visões e explicações a respeito do abastecimento energético na região.

A partir da revisão da literatura é possível identificar informações quantitativas, perspectivas e investimentos consideráveis na forma de recursos, que chegam diretamente aos cofres públicos, para que se tenham avanços significativos na geração e distribuição de energia movida a gás natural. No entanto, os procedimentos na maioria dos casos não ocorrem de forma transparente, e nem se tem esclarecimentos viáveis para a população como um todo.

Defende-se a ideia que a partir dessa pesquisa novos estudos podem ser realizados. Tendo em vista que ela pode trazer novos resultados, que futuramente necessitarão de novas análises e abordagens, além disso, ela pode contribuir diretamente nos estudos e análises da Ciência Geográfica. Portanto, tendo como base que já se passaram um período considerável de anos desde a implantação do gasoduto. Temse a necessidade de desenvolver um discurso, e análises com objetivos de verificar como está sendo a distribuição de energia nas cidades que fazem parte da linha, além disso, é essencial obter informações especificas se já se faz uso das usinas movidas a gás natural.

\section{MATERIAIS E MÉTODOS}

Os procedimentos adotados nessa pesquisa consistem em análises qualitativa e quantitativa em diferentes variáveis nas cidades da linha do gasoduto. Analisando assim todo contexto atual a respeito do abastecimento energético da região. È necessário também desenvolver abordagens teóricas tendo como base trabalhos já publicado e que analisam as questões energéticas na Amazônia, sobretudo no Estado do Amazonas.

Entende-se que o levantamento e a revisão bibliográfica, enquanto procedimento metodológico fornecem subsídios acadêmicos, que permitem um conhecimento mais extenso sobre o tema que será pesquisado. Criando com isso possibilidades para os recortes da pesquisa, definindo os campos em que a atuação irá requerer um maior nível de atenção, tanto em uma perspectiva teórica quanto prática. As informações são oriundas de trabalhos publicados em eventos, e extraídos em portais de Universidades, assim, se tem acesso a dissertações, teses, capítulos de livros, artigos científicos entre outros. Em relação a presente pesquisa, é necessário também 
desenvolver um levantamento documental junto a principal empresa responsável pelo abastecimento energético da região.

\section{RESULTADOS E DISCUSSÕES}

A presente pesquisa está em estágio de levantamentos teóricos para a construção das bases do primeiro capitulo da dissertação. Dessa forma, os resultados expostos são parciais e tem por base em analises desenvolvida em trabalhos já concluídos. Para se ter compreensão de como tem se dado o processo de distribuição de energia elétrica no Amazonas. Emanuel Maçal Cavalcante Soares Júnior, em seu trabalho intitulado: Indústria petrolífera e o crescimento econômico do Amazonas e de Manaus. Trás um discurso que possibilita um entendimento sobre o sistema de abastecimento energético no Estado.

O Estado do Amazonas integra o Sistema Isolado e consequentemente surge à necessidade de fontes de energias alternativas devido à geração hidráulica oriunda da hidrelétrica de Balbina não suprir a demanda da energia total consumida pelo Estado. (Soares Júnior, ano, p)

Em muitos casos o retardamento no transporte acarreta em resultados desconfortáveis para a população. Existem situações, que a concessionária que distribui energia, utiliza métodos conhecidos como racionamentos, dando prioridade para instituições públicas como escolas e hospitais. Como se sabe o Amazonas possui uma grande extensão territorial, e que esse é um dos fatores que acarretam na distribuição de energia a partir de sistemas isolados. Das 62 cidades do Estado, em todas estão inseridas usinas termelétricas tendo como principal responsável da concessionária Amazonas Energia SA.

Diante da extensão territorial, o Amazonas possui muitas de suas populações habitando nas margens dos rios, nas localidades denominadas comunidades ribeirinhas. Esses sujeitos são os que menos possuem acesso aos serviços de energia elétrica. Melo (2015) salienta que:

Nos Sistemas Isolados a principal forma de suprimento de energia elétrica para populações das sedes municipais, exceto algumas capitais dos estados, tem sido a geração térmica usando óleo Diesel. Nas comunidades dispersas predominam os sistemas motor gerador a Diesel, geralmente doado às comunidades pelas prefeituras municipais. (MELO, 2015 p. 27) 


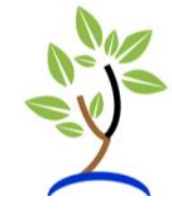

Os sistemas motor gerador movido a diesel, em muitos casos fazem parte dos planos políticos das prefeituras municipais. Que faz a doação do combustível e se responsabiliza pela manutenção do gerador, sobretudo nos lugares que não foram contemplados pelo Programa Luz Para Todos. Tem-se a necessidade de se desenvolver um discurso a respeito dos desafios para o abastecimento energético no Estado do Amazonas. Tendo em vista que de acordo com as abordagens referenciadas, isso ocorre a partir de sistemas isolados.

O Gasoduto, portanto, surge como alternativa para uma nova configuração no sistema de distribuição energética para o Estado do Amazonas. Espera-se que dos 62 municípios, 33 serão, eventualmente, ligado por causa de muitas linhas de distância, 15 deviam ser de 2013 e 13 nos anos seguintes. Quanto a 3800 comunidades rurais isoladas, eles terão sistemas autônomos (BROGIO, 2011).

A partir dessa informação, se torna ainda mais relevante desenvolver um levantamento que analise se os municípios contemplados estão sendo beneficiados, com essa nova alternativa de abastecimento energético.

Fato esse contraditório ao que consta no banco de dados da Agência Nacional de Energia Elétrica-ANEEL. Tendo em vista que de acordo com as informações expostas pela agência as cidades de Anamã, Anori, Caapiranga, Coari, Codajás, Iranduba e Manacapuru possuem usinas movidas a gás natural. De todo modo ressalta-se que a pesquisa de Bonfim tem dados de 2008, e devido ao período considerável de anos é possível que se tenham alterações nas informações.

\section{REFERÊNCIAS}

BRÓGIO, C. O Desafio da transição energética na Amazônia Brasileira. Revista Eletrônica de Ciência Ambiental. v 14. n 3. 1-15, 2014.

FROTA, W. M. Análise econômica da introdução do gás natural na matriz elétrica da cidade de Manaus. Dissertação de Mestrado. Faculdade de Tecnologia, Universidade Federal do Amazonas-UFAM, Manaus-AM, 91 p. 2011.

MELO, J. R. S.. Potencial de eficientização energética das micro e pequenas empresas industriais de Manaus-AM. Dissertação de Mestrado. Faculdade de Tecnologia. Universidade Federal do Amazonas-UFAM. Programa de. Manaus-AM. 161 p. 2011.

Recebido em 13/03/2018

Aceito em 30/05/2018 